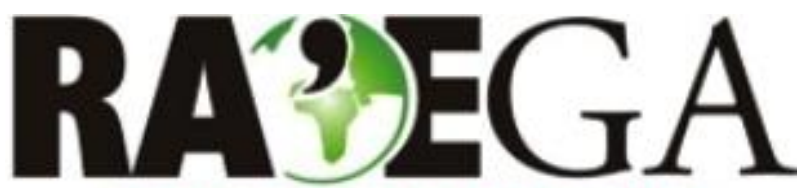

O ESPAÇO GEOGRÁFICO EM ANÁLISE

\title{
REDES DE SUPERMERCADOS E A GOVERNANÇA DO SETOR AGROALIMENTAR: A PRODUÇÃO DE FRUTAS NO NORDESTE BRASILEIRO ${ }^{1}$
}

\section{SUPERMARKET CHAINS AND THE GOVERNANCE OF AGROFOOD SECTOR: THE PRODUCTION OF FRUITS IN THE BRAZILIAN NORTHEAST}

\author{
Juscelino Eudâmidas Bezerra²
}

\section{RESUMO}

O objetivo do presente artigo é perscrutar o papel do capital comercial dos supermercados na governança da produção de frutas frescas no Nordeste brasileiro. O crescimento dos supermercados no contexto da rede de produção global ajudou a suplantar seu papel de mero estabelecimento comercial para exercer seu poder de comando no mercado competitivo de comercialização dos alimentos no mundo. A partir do exemplo da exportação de frutas no Nordeste brasileiro a pesquisa revelou a difusão de certificações internacionais entre os produtores como forma de atender as exigências das redes varejistas. Como resultado, verificou-se o surgimento de uma nova organização da produção e comercialização das frutas pautada no fortalecimento das estratégias de governança compreendendo o uso de certificações privadas como seu principal instrumento.

PALAVRAS-CHAVE: redes varejistas; frutas frescas, sistemas de auditoria e certificação; GLOBALG.A.P

\section{ABSTRACT}

The purpose of this article is to analyze the role of the commercial capital of supermarkets in the governance of the production of fresh fruits in north east Brazil. The growth of supermarkets in the global production network helped to overcome their role as mere commercial establishment to exercise its power of command in the competitive market of sale of food in the world. From the example of export of fruits in northeast Brazil the survey revealed the spread of international certifications among producers in order to meet the requirements of retailers. As a result, it was found the emergence of a new organization of production and marketing of fruit guided in strengthening governance strategies comprising the use of private certificates like the main tool.

KEY-WORDS: retailers; fresh fruit; audit and accreditation systems; GLOBALG.A.P

\footnotetext{
1 Pesquisa realizada com recursos do CNPq Ciências Humanas Edital 43/2013 e do Pós-Doutorado financiado pela CAPES.

${ }^{2}$ Universidade de Brasília, UNB, Brasília/DF, e-mail: jebgeo@unb.br
} 


\section{BEZERRA,J.E. \\ REDES DE SUPERMERCADOS E A GOVERNANÇA DO SETOR AGROALIMENTAR: A PRODUÇÃO DE FRUTAS NO NORDESTE BRASILEIRO}

\section{INTRODUÇÃO}

O objetivo do presente artigo é perscrutar o papel do capital comercial dos supermercados na governança da produção de frutas frescas no Nordeste brasileiro no contexto da formação da rede de produção global e do surgimento dos sistemas de auditoria e certificação. $O$ enfoque na questão da governança faz-se necessário pelo crescente interesse na conformação das relações de poder entre diferentes agentes econômicos, bem como a importância do consumo na definição de novas formas de exercício do poder.

A fruticultura se configura num dos principais setores do agronegócio na região Nordeste notadamente no sertão semiárido onde é possível encontrar muitas áreas que abrigam a produção de frutas frescas para o mercado interno e externo (BONANNO, CAVALCANTI, 2012; SELWYN, 2010). O desenvolvimento de modernas tecnologias de transporte e logística associadas ao maior consumo de frutas no mundo possibilitou o fortalecimento desta atividade como um setor chave para o processo de internacionalização das redes de produção agroalimentar.
A especialização produtiva da atividade da fruticultura no Nordeste colaborou para o surgimento de determinadas regiões produtivas do agronegócio - RPA ${ }^{3}$ (ELIAS, 2013) com destaque para as principais microrregiões de expansão da fruticultura (Figura 1), a saber: Petrolina - PE, Juazeiro - BA, Vale do Açu - RN, Mossoró - RN e Baixo Jaguaribe - CE.

\footnotetext{
3 O debate sobre a existência de regiões produtivas do agronegócio (RPA's) surgiu como indicação dos estudos conduzidos pela professora Denise Elias, coordenadora do Grupo de Pesquisa CNPq Globalização, Agricultura $e$ Urbanização (GLOBAU) do Curso de Geografia da Universidade Estadual do Ceará. Trata-se basicamente de delimitar um recorte regional que expresse as transformações territoriais propiciadas pelo agronegócio considerando a relação entre diferentes escalas geográficas e contextos socioespaciais; a reconfiguração urbana e regional; a relação cidade e campo; as mudanças na estrutura socioeconômica; as estratégias corporativas; e a regionalização dos fluxos materiais e imateriais envolvendo atividades industriais, comerciais e de serviços associadas à reprodução do agronegócio globalizado.
} 


\section{REDES DE SUPERMERCADOS E A GOVERNANÇA DO SETOR AGROALIMENTAR: A PRODUÇÃO DE FRUTAS NO NORDESTE BRASILEIRO}
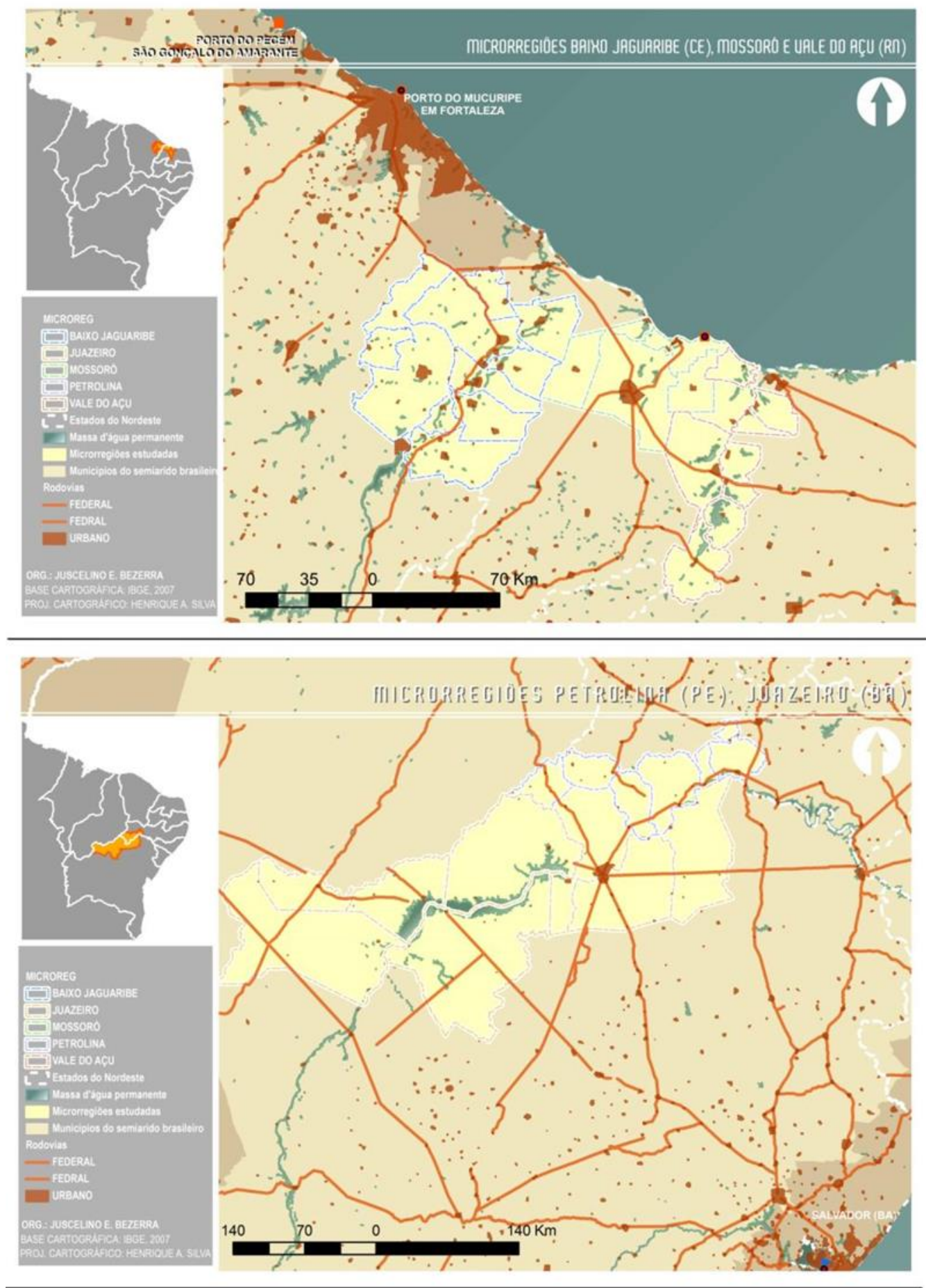

Figura 01 - Localização das áreas de estudo

As regiões em apreço representam parcela importante da produção de frutas no território nordestino sendo que as mesmas concentraram sozinhas em 2012 (PAM/IBGE), 95\% da quantidade produzida de melão (547.262 t), $66 \%$ de manga (782.365 t), $19 \%$ de uva
(289.977 t) e 35\% da produção de banana $(2.424,974 \mathrm{t})$ do Nordeste.

Fator decisivo para o crescimento da atividade, a atuação do Estado foi fundamental na medida em que promoveu portentosos investimentos. Destacam-se a construção de 


\section{REDES DE SUPERMERCADOS E A GOVERNANÇA DO SETOR AGROALIMENTAR: A PRODUÇÃO DE FRUTAS NO NORDESTE BRASILEIRO}

perímetros irrigados públicos e seus sistemas de irrigação (canais, estações de bombeamento, infraestrutura elétrica, estradas etc.), bem como a criação de instituições públicas de apoio à realização das atividades do agronegócio frutícola. O quadro edafoclimático também propiciou o plantio de culturas adaptadas ao sertão semiárido. Nesse contexto, ao contrário da imagem da seca e das vicissitudes da agricultura de sequeiro dependente das chuvas, a intervenção técnica pela irrigação permitiu a ruptura do sertão semiárido como obstáculo natural à regulação econômica do território (CASTRO, 1996).

Como resultado, no Nordeste encontram-se atualmente importantes áreas de produção de frutas totalmente conectadas à rede de produção global pela demanda por produtos frescos para o consumo in natura, notadamente uva, manga, melão e banana. Grande parte da produção é exportada para a Europa, com destaque para os Países Baixos (Holanda), Alemanha e Inglaterra.

A articulação das regiões produtivas do agronegócio na rede de produção global (COE DICKEN, HESS, 2008; COE 2009) caracteriza-se, entre outros fatores, pela integração entre vários setores econômicos em diferentes escalas geográficas. Como corolário, verificou-se nos últimos anos um crescimento econômico expresso no incremento do número de estabelecimentos de comércio e serviços e o aumento populacional nas principais cidades de porte médio. Parte desse processo evidencia também a existência de determinados centros urbanos cuja função de atendimento ao agronegócio se sobrepõem sobre as demais funções, constituindo-se verdadeiras cidades do agronegócio (ELIAS, 2012, 2007).

O avanço do agronegócio, ao modernizar a produção da riqueza, transformou a maneira como a sociedade lida com a terra em determinados lugares, extraindo uma riqueza obtida diretamente da exploração comercial, das trocas internacionais, da formação de conglomerados empresariais imersos na globalização (BEZERRA, 2012, p.111). Neste ínterim, as relações de trabalho também são modificadas passando a apresentar nítidos contornos que expressam o processo de modernização da agricultura, especialmente a partir da criação de um mercado de trabalho capitalista vis-à-vis a intensificação dos conflitos sociais envolvendo a questão fundiária e a luta pela terra e pela água através da atuação dos movimentos sociais (BEZERRA; ELIAS, 2011).

Diante do contexto supracitado, é mister destacar que as mudanças verificadas na dinâmica das regiões produtivas do agronegócio expressam, na verdade, a disseminação de uma nova lógica na produção do espaço. Por nova lógica entende-se a atuação de novos agentes econômicos responsáveis por ditar importantes transformações na dinâmica econômica e social nos territórios da produção.

Dentre os novos agentes econômicos, cujo papel de controle e governança tem se ampliado nos últimos anos, destacam-se justamente as redes varejistas (supermercados).

\section{MATERIAIS E MÉTODOS}

Para a realização da pesquisa cujo artigo em questão visa expor os resultados alcançados, foram utilizados determinados procedimentos metodológicos de modo a apreender aspectos da realidade dos territórios da produção de frutas no Nordeste brasileiro, bem como sua relação comercial com os principais compradores e fornecedores de frutas para as redes de supermercados que atuam no mercado europeu. Para tal, a metodologia foi organizada em três eixos, a saber: a organização de uma pesquisa bibliográfica, a construção de um banco de dados estatísticos vinculados à elaboração de mapas e cartogramas. Por fim, a realização de trabalhos de campo no Brasil e na Europa.

No primeiro momento procedeu-se uma pesquisa bibliográfica em bibliotecas de universidades e demais órgãos públicos no Brasil com o intuito de coletar livros, artigos, documentos sobre a temática do estudo sempre que possível realizando a pesquisa também nos municípios no qual ocorreram os trabalhos de campo. Em paralelo, a consulta ao portal de 


\section{REDES DE SUPERMERCADOS E A GOVERNANÇA DO SETOR AGROALIMENTAR: A PRODUÇÃO DE FRUTAS NO NORDESTE BRASILEIRO}

periódicos disponibilizados pela CAPES foi de extrema importância. É importante destacar, e isso configura um primeiro resultado obtido na pesquisa, a relativa carência de estudos no Brasil que se debruçam na análise das redes varejistas desde a perspectiva socioeconômica. Fato este decisivo para que houvesse um aprofundamento na busca por artigos e livros em línguas estrangeiras.

Desse modo, foi possível encontrar um conjunto de autores em vários países que realizam pesquisas sobre a temática dos supermercados, das certificações e da dinâmica do setor agroalimentar e que dispõem de uma produção bibliográfica ampla e sistemática. Particularmente pós década de 2000 quando temos a difusão das certificações internacionais envolvendo vários produtos da agricultura de exportação no mundo.

O banco de dados utilizado na pesquisa foi construído no primeiro momento a partir da necessidade de caracterizar a evolução da produção de frutas nas principais microrregiões da fruticultura no Nordeste. A principal fonte de dados nesse quesito foi a Produção Agrícola Municipal (PAM) do Instituo Brasileiro de Geografia e Estatística (IBGE) com as variáveis quantidade produzida, área plantada e valor da produção.

No site do Ministério das Relações Exteriores da Holanda através do Centre for the Promotion of Imports from developing countries - CBI encontra-se uma importante fonte de dados sobre o consumo e a importação/exportação de frutas para a Comunidade Europeia proveniente de países em desenvolvimento. A partir da qual se obteve dados sobre o consumo de frutas tropicais nos principais mercados da Europa.

Outra base utilizada foi a da Relação Anual de Informações Sociais (RAIS) do Ministério do Trabalho e Emprego mediante os dados sobre o estoque de empregos formais por setor de atividade econômica. Com a RAIS obteve-se o ranking nacional dos municípios com maior estoque de empregos formais no setor da agropecuária.
A dinâmica do setor varejista foi lida e interpretada tendo como base informações coletadas no Planet Retail Report, empresa privada líder mundial na área de pesquisa para o setor do varejo. Organiza anualmente relatórios sobre as principais redes varejistas do mundo com informações sobre o total de vendas e a concentração do varejo por cada continente e país.

Dentre as inúmeras certificações encontradas no setor agroalimentar nos últimos anos, optou-se por analisar especificamente a certificação GLOBALG.A.P criada por um grupo de supermercados na Europa na década de 1990. Para o levantamento de informações primárias e secundárias recorreu-se às entrevistas realizadas com representantes da certificação supracitada, dados disponibilizados pelo site oficial do GLOBALG.A.P, como também das empresas certificadoras no Brasil além de informações dos produtores certificados. A sistematização dos dados associados ao GLOBALG.A.P foi fundamental para a confecção de cartogramas da distribuição dos produtores certificados no Brasil, de modo a identificar a importância das regiões produtoras de frutas.

O terceiro e último eixo de operacionalização da pesquisa foi representado pela consecução dos trabalhos de campo. O foco dos trabalhos de campo foram as áreas com maior destaque na produção de frutas para exportação tais como os municípios da RIDE de Petrolina (PE)/ Juazeiro (BA), as microrregiões de Mossoró e Vale do Açu no Rio Grande do Norte e do Baixo Jaguaribe no Ceará. Na Europa realizamos entrevistas durante a Fruit Logistica, a maior feira de frutas e vegetais do mundo realizada em Berlim. No espaço da Fruit Logistica concentram-se os principais produtores e fornecedores de frutas do mundo, bem como os representantes das principais certificações internacionais do setor agroalimentar.

\section{RESULTADOS E DISCUSSÃO}

\subsection{O NOVO PAPEL DOS SUPERMERCADOS}

Nos últimos anos os supermercados suplantaram seu papel de mero estabelecimento 


\section{REDES DE SUPERMERCADOS E A GOVERNANÇA DO SETOR AGROALIMENTAR: A PRODUÇÃO DE FRUTAS NO NORDESTE BRASILEIRO}

comercial do varejo alimentar para exercer seu poder de comando numa extensa e globalizada rede agroalimentar. Lawrence e Burch (2007) destacam que os supermercados cada vez mais determinam o que é produzido, onde, sob qual modelo e os canais de comercialização transformando completamente a forma como a sociedade passou a se relacionar com os alimentos.

Paralelo ao fortalecimento dos supermercados é possível verificar igualmente o crescimento das críticas direcionadas ao setor. Lawrence e Burch (2007) destacam ainda que as redes varejistas têm sido largamente contestadas por seu tratamento com os fornecedores; as sucessivas tentativas de reduzir ao máximo os preços tendo como resultado o aumento na exploração da força de trabalho em países com baixa proteção aos trabalhadores; sua influência na mudança da própria natureza das compras; a formação de oligopólios e o consequente fechamento de pequenos estabelecimentos e feiras; e, por fim, seu papel como "novas autoridades alimentares" (DIXON, 2007, p.29) na promoção de dietas obesogênicas, contribuindo para o aumento de casos de doenças do coração e diabetes.

Mediante o poder de articulação e interação escalar dos supermercados, possibilitado pelo papel de "dirigente" da rede de produção agroalimentar, torna-se fundamental identificar as ligações entre diferentes escalas geográficas a partir do consumo. Tal desafio exige de nós um olhar mais apurado acerca da complexa trama de relações existentes na organização das atividades econômicas globais marcadas por um forte processo de integração. Essa integração, para além de uma associação meramente econômica inerente ao desenvolvimento da produção e do consumo, é uma integração que cada vez mais ganha elementos sociais, políticos e culturais (LESLIE, 2009, p.269).

Nesse sentido, devemos avançar no entendimento das atividades econômicas globais não se restringindo apenas aos mecanismos econômicos que a regulam atentando para as formas de controle e de poder.

O processo de globalização econômica no contexto das redes de produção global traz redefinições constantes nas estruturas de poder do mercado. A rede de produção envolve uma multiplicidade de agentes econômicos, formais e informais, institucionais e não institucionais e uma gama de Estado-Nações operando numa economia global. Portanto, sua consecução requer a análise de uma complexa trama de poderes uma vez que, se todos estão dispostos na rede, isso não necessariamente significa que todos têm o mesmo peso político e econômico. Nesse sentido, muitos estudiosos veem a necessidade de atentarmos para as formas de controle social, político e econômico existentes no contexto das redes de produção.

No caso da rede de produção das frutas, e arriscamos afirmar também para toda a rede agroalimentar, as formas de poder e controle social são fortemente influenciadas pela ação direta e indireta das redes varejistas, leia-se: os grandes supermercados. São eles os responsáveis por imprimir uma nova organização social da produção, definindo padrões de produção, circulação, distribuição e consumo.

Esse papel de destaque somente foi possível pela formação de oligopólios e como desdobramento mais evidente, o comando de importantes mercados por um pequeno grupo de empresas. Desde o berço da economia capitalista, sabemos que o controle do mercado por um pequeno número de empresas não reúne somente os rendimentos, mas, sobretudo, permite a concentração do poder. Por essa razão, a literatura econômica tem buscado compreender as formas de poder no interior das redes de produção global. Uma possibilidade de leitura desse processo, disseminada na literatura internacional, pode ser verificada a partir da discussão sobre a governança (RHODES, 1996,2007; STOKER, 1998; HUBBARD et al, 2002).

Não obstante o caráter polissêmico do debate associado à ideia de governança, podemos admitir a existência de aspectos chaves na discussão, particularmente o fato de que a 


\section{REDES DE SUPERMERCADOS E A GOVERNANÇA DO SETOR AGROALIMENTAR: A PRODUÇÃO DE FRUTAS NO NORDESTE BRASILEIRO}

governança não pode ser confundida como um mero conjunto de ferramentas gerenciais vinculado ao Governo (STOKER, 1998, p.18). No sentido que queremos destacar, a governança pode ser entendida através das formas de controle exercidas por diferentes agentes públicos e/ou privados, atores sociais não estatais que influenciam na coordenação social, política e econômica de importantes atividades.

Quando pensamos as redes de produção global, torna-se necessário averiguar quais as formas de controle que influenciam na organização da rede, de forma a entendermos as tramas de poder existentes nas operações do capital. Nosso intuito em apresentar essa discussão é conhecer com maior nível de detalhe como o capital comercial vem se apoderando de diversos mecanismos para a realização de suas atividades e quais são os agentes que têm reconfigurado a dinâmica do setor da fruticultura.

\subsection{A DIFUSÃO DAS CERTIFICAÇÕES COMO INSTRUMENTO DE GOVERNANÇA}

A escalada das redes varejistas representa a constatação não somente de seu poderio econômico, como também político. Como resultado dessa mudança, os autores Fuchs; Kalfagianni; Arentsen (2009, p.31) apontam para a convergência de três tendências na organização atual das redes varejistas. A primeira delas diz respeito à formação de um oligopólio, mediante a atuação de importantes grupos no mercado internacional.

As principais redes, notadamente as líderes mundiais Walmart e Carrefour, participam cada vez mais dos mercados internacionais. A América Latina representa um vigoroso exemplo da dominância das multinacionais, no qual as três principais empresas com maior receita anual são estrangeiras (Planet Retail Report, 2012). A presença dessas gigantes em muitos mercados externos foi fruto da fusão e aquisição de empresas nacionais, fato esse que se tornou uma estratégia comum para ampliar a participação no mercado e aniquilar a concorrência.
$\mathrm{Na}$ Europa, onde encontramos um mercado extremamente competitivo, a oligopolização alcança números alarmantes. Vorley (2007) apresenta dados sobre a concentração do varejo. Nas maiores economias, as quatro principais redes de supermercado concentravam as maiores proporções: $66,7 \%$ das vendas na Alemanha, $60 \%$ na Franca, $70,6 \%$ na Inglaterra, 62,5\% na Espanha, 82,6\% na Holanda e de até $99,5 \%$ na Noruega. Como resultado, Lawrence e Burch (2007) apontam que em 2004 as trinta principais redes de supermercado do mundo controlavam $33 \%$ do total mundial das vendas de alimentos.

A segunda tendência que caracteriza a expansão dos supermercados é o controle da cadeia de produção desde a fazenda até a prateleira. Desse modo, os grandes supermercados desenvolveram uma complexa logística de gerenciamento dos seus fornecedores. Atualmente, os grandes supermercados comercializam uma ampla variedade de produtos, desde alimentos até eletrodomésticos, e os consumidores, paulatinamente, passam a procurar os supermercados para atender as necessidades básicas de suprimento. Desse modo, as redes varejistas, pelo seu poder de compra e de acesso aos consumidores, ganharam força na negociação e definição dos preços junto aos produtores e fornecedores.

Por fim, a terceira tendência é a do desenvolvimento da competição centrada não apenas na disputa pelo menor preço, mas também na oferta de produtos de qualidade. A partir daí, testemunhamos a chamada guerra de preços pari passu a consolidação das chamadas políticas de qualidade calcadas na promoção de selos e certificações que atestam a qualidade dos produtos.

Em suma, a combinação entre força oligopólica, controle das redes de produção e distribuição, definição dos preços e a conquista da credibilidade dos consumidores mediante a política de qualidade dos produtos fortaleceram o papel de destaque dos supermercados na governança das redes de produção. Tornando um 


\section{BEZERRA,J.E. \\ REDES DE SUPERMERCADOS E A GOVERNANÇA DO SETOR AGROALIMENTAR: A PRODUÇÃO DE FRUTAS NO NORDESTE BRASILEIRO}

desafio para os pesquisadores avaliar a extensão dos impactos sociais e econômicos engendrados pelas grandes redes varejistas.

Naquilo que concerne à comercialização de frutas no mundo a crescente multiescalaridade da rede de produção da fruticultura revelou o papel de destaque do mercado europeu não somente nos fluxos de exportação e no aumento do consumo ${ }^{4}$ de frutas, mas também na organização das redes de governança.

Desse modo, são nos principais países consumidores, tais como Alemanha, Reino Unido, França e Países Baixos, onde podemos encontrar a centralização das decisões que envolvem as formas de governança exercidas por um conjunto de agentes (supermercados, fornecedores, importadores, consumidores). Esses passam a exercer maior relação de poder no interior da rede de produção, sobretudo, quando consideramos a crescente regulação realizada pelo setor privado mediante a adoção de esquemas de auditoria e certificação.

Tais iniciativas configuram-se como estratégias dos supermercados no intuito de garantir o maior controle do processo produtivo e atender às expectativas de um novo perfil de consumidor, muito mais propenso a escolher produtos que respeitem o meio ambiente e as questões trabalhistas nas regiões onde as frutas são produzidas.

\footnotetext{
4 Segundo dados do Ministério de Relações Exteriores da Holanda (país que mais importa frutas do Brasil e responsável pela distribuição da maior parte das frutas no mercado europeu), o consumo per capita de banana na Comunidade Europeia em 2009 foi de 9,4 kg, com destaque para o Reino Unido, com $14 \mathrm{~kg}$, e a Alemanha com 11,8 kg. Para a manga, uma fruta ainda considerada exótica, a média foi de $0,4 \mathrm{~kg}$ e o destaque foi a Holanda, com o consumo per capita de 2,1 kg. A média do consumo per capita de melão na Europa foi de $4,7 \mathrm{~kg}$, com destaque para a França, com $6,3 \mathrm{~kg}$. Por fim, a uva foi a única cultura na qual não existem dados precisos sobre a média de consumo per capita para a uva de mesa na Europa, visto ser uma cultura de larga difusão e pelo fato de 70 a $75 \%$ da uva ser destina para o processamento. No entanto, em 2009, os países da Europa que mais consumiram uvas (uvas de mesa ou processadas) foram respectivamente Itália, França e Espanha.
}

O papel dos supermercados nesta nova configuração econômica da rede agroalimentar supera a simples comercialização e distribuição de alimentos e passa a influenciar diretamente os padrões de produção e de consumo. No caso das frutas, os supermercados criaram um sistema de certificação baseado em auditorias para assegurar que seus fornecedores seguem as principais normativas das Boas Práticas Agrícolas (DORR, 2010, p. 550).

Quando os supermercados adentram, definitivamente, na arena da regulação via profusão de certificações privadas, testemunhamos novas formas de governança e de governamentalidade ${ }^{5}$ (HUXLEY, 2008; PEGLER, 2011). Fuchs e Kalfagianni (2010, p.13) apontam as causas da emergência das regulações privadas no setor dos alimentos. Para as autoras, o surgimento e a difusão da regulamentação privada dos alimentos dão-se em função do poder estrutural (material) dos supermercados, como também do poder das redes varejistas em criar uma legitimidade entre os consumidores. É dessa forma, segundo as autoras, que os supermercados se tornam atores políticos prontos para disputar sua efetividade na sociedade.

Para Henson (2008, p. 66), o aumento no temor dos consumidores quanto à segurança e à qualidade dos alimentos, sobretudo, após o

\footnotetext{
5 De acordo com Huxley (2008, p. 1635), o termo governamentalidade cunhado por Focault leva em consideração dois aspectos: uma análise histórica das lógicas de governo por parte do Estado e a investigação sobre as formas de auto-governo e governo dos outros. De uma forma geral, a governamentalidade atua na ação de outras pessoas com o objetivo de criar comportamentos específicos, hábitos e subjetividades. Lee Pegler (2011, p.27), destaca a governamentalidade como quadro teórico importante para compreender como as mensagens, regras e normas são estabelecidas, transmitidas e contestadas através das redes de produção, mormente após a utilização de padrões de qualidade. Os supermercados têm adotado os padrões de qualidade para reforçar sua política de relação com os fornecedores. Por sua vez, estes últimos incorporam um novo repertório de práticas e ações de modo a atender as normas impostas pelas redes varejistas.
} 


\section{REDES DE SUPERMERCADOS E A GOVERNANÇA DO SETOR AGROALIMENTAR: A PRODUÇÃO DE FRUTAS NO NORDESTE BRASILEIRO}

escândalo da vaca louca e da proliferação de alimentos transgênicos, contribuiu para erodir a confiança na fiscalização por parte do poder público. Portanto, as grandes redes de supermercados começaram a competir entre si no mercado nacional e internacional utilizando estratégias de diferenciação das mercadorias com o foco na segurança e qualidade, uma vez que as normas públicas não oferecem possibilidade de diferenciação do produto.

O fortalecimento dos esquemas privados de certificação permitiu então a criação de normas, padrões e regras, muitas vezes, tidos como mais rígidos do que o dos órgãos públicos. Embora saibamos que as normas, de maneira geral, seguem os preceitos e orientações da Codex Alimentarius, criada pela Organização das Nações Unidas para a Alimentação e a Agricultura (FAO).

A partir da contestação quanto à credibilidade dos órgãos fiscalizadores da esfera pública, e paralelamente, a maior cobrança por parte dos consumidores organizados em torno de associações, ONG's e movimentos sociais, as certificações privadas começaram a se difundir e estabelecer seus próprios códigos de conduta, particularmente no que se refere ao tema da segurança alimentar. Para Henson e Humphrey (2011, p.151), a criação desses padrões, necessariamente, envolve o estabelecimento de uma base para reivindicações sobre as práticas a serem adotadas com relação ao modo como o alimento deve ser produzido, transportado e processado. Igualmente, abrange também formas de monitoramento e aplicação, realizadas por uma segunda e cada vez mais terceira parte. Em suma, os autores destacam que:

...os padrões privados envolvem não somente a especificação de quais resultados serão alcançados, mas também estabelecem um conjunto de regras para mostrar como devem ser realizados, uma estrutura de governança da certificação e aplicação, bem como um sistema de geração e aprovação de mudanças em cada um dos elementos como o padrão de evolução ao longo do tempo. (HENSON, HUMPHREY, 2011, p. 151, tradução livre).

Foi nesse contexto, que a partir da década de 1990 surgiram inúmeras certificações privadas. Henson e Humphrey (2011, p. 154) citam exemplos de três tipos de certificação privada nas redes agroalimentares, quais sejam: a) certificações de empresas individuais: Tesco Nature's Choice; Garantia de Origem Carrefour; Field to fork Marks \& Spencer; Albert Heijn BV; b) certificações coletivas nacionais: Assured Food Standards (UK); British Retail Consortium Global Standard; Freedom Food (UK); c) certificações coletivas internacionais: International Food Standard; Safe Quality Food e; Global GAP. Vale ressaltar que em todos os esquemas de certificação, as redes varejistas estão diretamente associadas.

Concomitante ao surgimento de novas certificações verificou-se o crescimento da comercialização pelas grandes redes de supermercado de produtos certificados com o selo do Comércio Justo (Fair Trade) e também de produtos orgânicos. Conforme aponta Hughes (2005), mesmo os produtos considerados alternativos por empreender uma nova forma de comercialização que protege os pequenos produtores dos abusos cometidos por atravessadores, garantindo um preço justo e maior responsabilidade social, tais produtos são hoje comercializados, em sua grande maioria, pelas grandes redes de supermercados.

Diante do contexto supracitado qual a participação das regiões produtivas do agronegócio na rede de produção da fruticultura comandada pelos supermercados?

Nos últimos anos assistiu-se a criação de um conjunto bastante heterogêneo de sistemas de certificação privados (HAVINGA, 2006). De todas as certificações hoje existentes, aquela que obteve maior difusão foi sem dúvida a GLOBALG.A.P ,anteriormente denominada EurepGap (CAMPBELL, LAWRENCE, SMITH,2006). GLOBALG.A.P é uma organização privada, formada em 1997 por um grupo de redes 


\section{REDES DE SUPERMERCADOS E A GOVERNANÇA DO SETOR AGROALIMENTAR: A PRODUÇÃO DE FRUTAS NO NORDESTE BRASILEIRO}

varejistas $^{6}$ na Europa com o objetivo de criar normas voluntárias para a certificação de produtos agrícolas e garantir credibilidade e segurança ao público consumidor assegurando a comercialização de produtos saudáveis.

De pronto, faz-se necessário afirmar que a certificação GLOBALG.A.P surgiu com o intuito de simplificar $O$ atendimento às normas regulamentadoras por parte dos fornecedores. Ao invés da criação de vários selos, com diferentes metodologias e práticas e a avaliação acerca da origem de cada produtor e/ou fornecedor, foi pensada uma forma de harmonizar todas as práticas agrícolas e em comum acordo acatar a emissão da certificação via auditoria como uma forma fidedigna de controle da produção.

Numa medida bastante astuta, os supermercados transferiram paulatinamente a responsabilidade e os custos da comprovação sobre a sanidade dos alimentos e o respeito a determinadas práticas sociais e ambientais para os produtores e fornecedores. Porém, todo o corpo de regras foi criado pelos supermercados, embora, atualmente, a organização GLOBALG.A.P tenha correspondido às exigências legais da União Européia para que haja maior abertura dos demais envolvidos na rede de produção agroalimentar, tais como produtores e fornecedores. (KALFAGIANNI; FUCHS, 2011).

As normas estabelecidas pela certificação são criadas em parceria entre produtores (grandes grupos empresariais no setor da produção) e retalhistas (grupos de comercialização no varejo) com o intuito de harmonizar os requisitos de produção conforme as orientações adotadas pelo código de Boas Práticas Agrícolas.

\subsection{GLOBALG.A.P: NOVO CÓDIGO DE CONDUTA?}

A emissão do certificado GLOBALG.A.P é realizada por empresas certificadoras

\footnotetext{
6 Entre as redes que compõem a organização GLOBALG.A.P destacam-se: Carrefour (França), Walmart (Estados Unidos), Tesco (Inglaterra), Ahold (Holanda), Edeka (Alemanha), LIDL (Alemanha), Aldi (Alemanha), Asda (Inglaterra), Marks and Spencer (Inglaterra), Rewe (Alemanha).
}

cadastradas pela organização mediante auditorias e visitas de inspeção nas fazendas produtoras. $O$ intuito é certificar o atendimento a todas as regras contidas nos pontos de controle presentes no checklist adotado pela organização.

$$
\text { A certificação GLOBALG.A.P é a }
$$
certificação privada com maior difusão internacional, sendo considerada pelos produtores como um requisito fundamental para o acesso ao mercado europeu. Segundo informações disponíveis no relatório anual da organização, em 2011, o número total de produtores com a certificação GLOBALG.A.P cresceu 9,5\% com relação a 2010. Em números absolutos este resultado significou um aumento de 102.300 para 112.600 produtores certificados. Sua abrangência geográfica também chama atenção, pois os produtores estão distribuídos em 113 países. A grande maioria desses (74\%) encontra-se na Europa; 11\%; nas Américas; $9 \%$ na Ásia; 4\% na África e; 2\% na Oceania. Os países que apresentam a maior quantidade de produtores certificados são a Espanha, Itália e Grécia.

No Brasil, segundo informações coletadas na entrevista com a organização, são 433 produtores certificados, sendo 290 no setor de frutas e vegetais para o ano de 2011. Ao observar a distribuição geográfica dos produtores certificados no Brasil fica patente a importância das áreas de produção localizadas na região Nordeste com especial destaque para a RIDE Petrolina-Juazeiro e Mossoró no Rio Grande do Norte.

Considerando o total de 286 produtores, excluindo quatro, cuja localização exata não foi identificada nos registros obtidos, verificou-se que $71 \%$ dos produtores estão situados na Região Nordeste (Figura 1). Ao considerar apenas os municípios das regiões produtivas do agronegócio da fruticultura, a participação total foi de $63 \%$. Individualmente, o destaque foi para - município de Petrolina (PE) que sozinho foi responsável por concentrar um terço (33\%) de todos os produtores certificados pelo GLOBALG.A.P no Brasil. É importante ressaltar ainda que em 2011 o município de Petrolina (PE) 


\section{REDES DE SUPERMERCADOS E A GOVERNANÇA DO SETOR AGROALIMENTAR: A PRODUÇÃO DE FRUTAS NO NORDESTE BRASILEIRO}

liderou o ranking nacional de municípios com o maior número de postos formais no setor da agropecuária com 10.889 empregos de acordo com informações da Relação Anual de Informações Sociais (RAIS) do Ministério do Trabalho e Emprego.

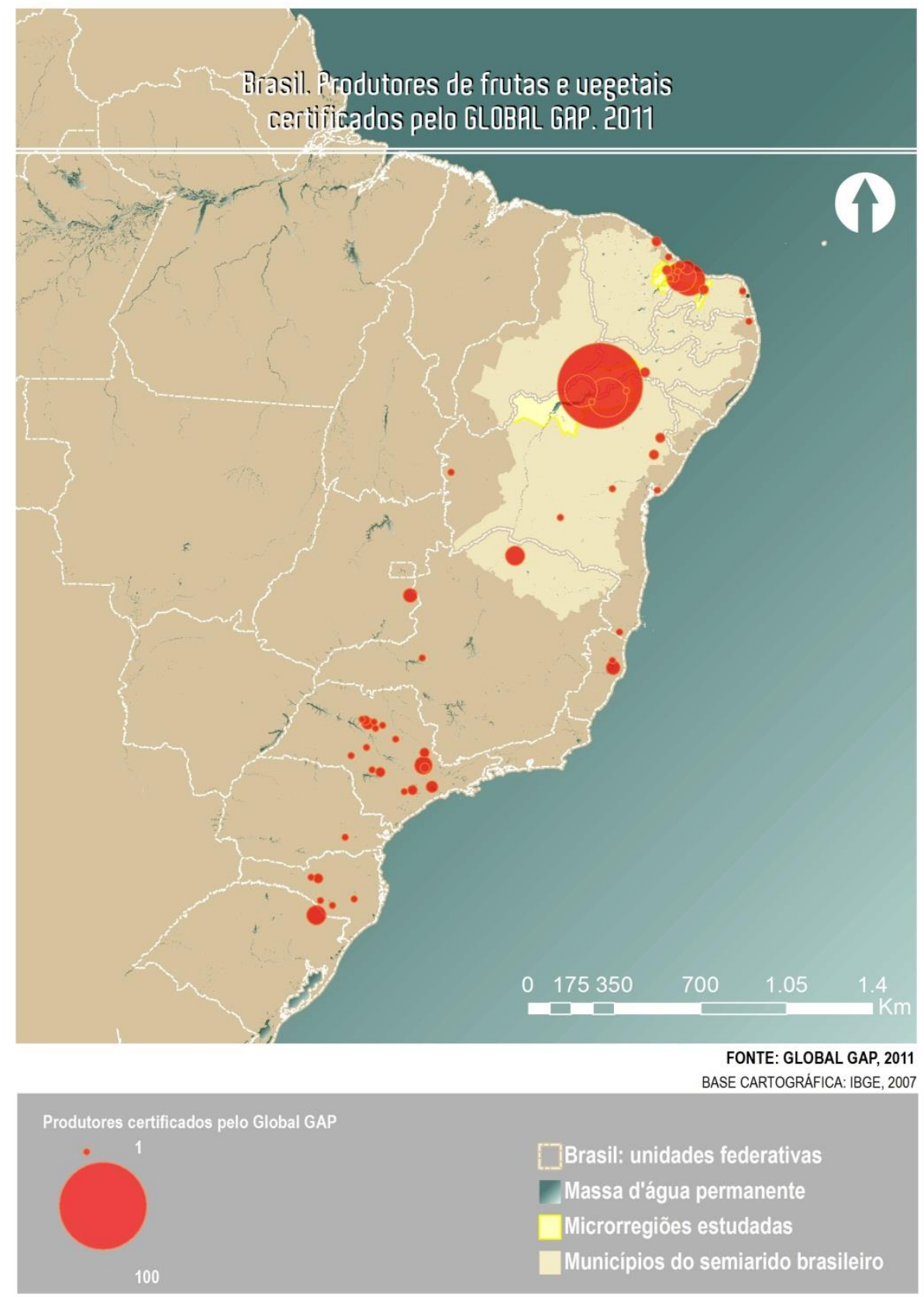

Figura 02 - Produtores certificados pelo GLOBALG.A.P no Brasil-2011. Fonte: Trabalho de campo.

A certificação GLOBALG.A.P representa o primeiro passo para aqueles produtores que desejam participar da exportação de frutas para o mais importante mercado desses produtos tropicais, ou seja, a Europa. A não existência da certificação GLOBALG.A.P representa uma primeira barreira à exportação.
A importância dada ao GLOBALG.A.P advém do próprio contexto no qual as frutas são comercializadas. As empresas que realizam a compra desses alimentos junto aos produtores já têm como orientação comprar apenas de estabelecimentos que possuam a certificação GLOBALG.A.P. É por meio da certificação que os compradores e, por sua vez, os supermercados 


\section{REDES DE SUPERMERCADOS E A GOVERNANÇA DO SETOR AGROALIMENTAR: A PRODUÇÃO DE FRUTAS NO NORDESTE BRASILEIRO}

têm a "garantia" de que o produtor segue critérios básicos de produção, estando de acordo com as Boas Práticas Agrícolas.

Para a obtenção da certificação os produtores recebem inspeção de empresas de auditoria. Ou seja, os órgãos de certificação, tais como GLOBALG.A.P e/ou redes de supermercados, a exemplo da rede Tesco, contratam terceiros (empresas de auditorias) para que elas possam aplicar os respectivos códigos e normas para a emissão dos certificados.

Quadro 01 - Empresas Certificadoras - Setor Fruticultura - 2012

\begin{tabular}{|c|c|c|}
\hline Empresa & Origem & Certificações Emitidas \\
\hline SANTEC/ Primus Lab & Brasil & GLOBALG.A.P, TESCO, HACCAP, USAGAP \\
\hline TUV RHEILAND & Alemanha & GLOBALG.A.P, TESCO, HACCP, PIF \\
\hline $\begin{array}{l}\text { BUREAU VERITAS } \\
\text { CERTIFICATION }\end{array}$ & França & GLOBALG.A.P, BRC, HACCP \\
\hline SGS & França & GLOBALG.A.P \\
\hline WQS Certificação de Produtos & Brasil & GLOBALG.A.P, TESCO \\
\hline
\end{tabular}

O mercado das auditorias é disputado por empresas nacionais e internacionais. A concorrência entre as empresas dá-se pela oferta do menor custo com a relação à certificação. $O$ valor médio de uma certificação do GLOBALG.A.P gira em torno de $\mathrm{R} \$ \mathbf{1} 100,00$. A empresa pernambucana Santec, credenciada pela
A partir das informações coletadas no trabalho de campo, obteve-se a lista das principais certificadoras que atuam nas regiões de produção de frutas no Nordeste, especialmente no Vale do São Francisco. Após contato com as respectivas certificadoras, organizamos informações sobre a origem das empresas e as certificações emitidas (QUADRO 1).

americana Primus Lab, detém o maior número de clientes com certificação GLOBALG.A.P nas regiões produtivas do agronegócio da fruticultura.

A seguir, temos uma pequena amostra (QUADRO 2) com as principais empresas produtoras de frutas e as certificações adotadas.

Quadro 02 - Empresas certificadas nas microrregiões de expansão da fruticultura no Nordeste

\begin{tabular}{|c|c|c|c|}
\hline Nome da empresa & $\begin{array}{l}\text { Principais } \\
\text { produtos }\end{array}$ & Localização & Certificações \\
\hline Del Monte Fresh & $\begin{array}{l}\text { Banana, } \\
\text { Melão }\end{array}$ & $\begin{array}{l}\text { Vale do Açu } \\
\text { (RN) e Baixo } \\
\text { Jaguaribe (CE) }\end{array}$ & GLOBALG.A.P, Tesco \\
\hline Queiroz Galvão Alimentos & $\begin{array}{l}\text { Uva, } \\
\text { Manga }\end{array}$ & Petrolina (PE) & $\begin{array}{l}\text { GLOBALG.A.P, Tesco,HACCP, } \\
\text { PIF,USAGAP, ISO } 9001\end{array}$ \\
\hline Expofruit Brasil & $\begin{array}{l}\text { Uva sem } \\
\text { semente }\end{array}$ & Petrolina (PE) & Global GAP, Tesco \\
\hline Agrícola Famosa & $\begin{array}{l}\text { Melão, } \\
\text { Melancia }\end{array}$ & $\begin{array}{l}\text { Mossoró (RN) } \\
\text { e Baixo } \\
\text { Jaguaribe (CE) }\end{array}$ & $\begin{array}{l}\text { GLOBALG.A.P, Tesco, Marks \& Spencer; } \\
\text { HACCP }\end{array}$ \\
\hline $\begin{array}{l}\text { Meneghel Hassuike } \\
\text { Agropecuária }\end{array}$ & Uva & Juazeiro (BA) & GLOBALG.A.P \\
\hline Fazenda Fortaleza & $\begin{array}{l}\text { Uva e } \\
\text { Manga }\end{array}$ & Juazeiro (BA) & $\begin{array}{l}\text { GLOBALG.A.P, Tesco, Produção Integrada } \\
\text { de Frutas (PIF), Marks \& Spencer; HACCP, }\end{array}$ \\
\hline
\end{tabular}


BEZERRA,J.E.

REDES DE SUPERMERCADOS E A GOVERNANÇA DO SETOR AGROALIMENTAR: A PRODUÇÃO DE FRUTAS NO NORDESTE BRASILEIRO

\begin{tabular}{|l|l|l|l|}
\hline & & & ETI \\
\hline UGBP & $\begin{array}{l}\text { Mamão } \\
\text { Papaya }\end{array}$ & Juazeiro (BA) & $\begin{array}{l}\text { GLOBALG.A.P, USAGAP, Produção } \\
\text { Integrada de Frutas (PIF). }\end{array}$ \\
\hline Fazenda Special Fruit & $\begin{array}{l}\text { Uva e } \\
\text { Manga }\end{array}$ & Juazeiro (BA) & GLOBALG.A.P; TESCO \\
\hline Fazenda Área Nova & $\begin{array}{l}\text { Uva e } \\
\text { Manga }\end{array}$ & Petrolina (PE) & GLOBALG.A.P,Tesco, Marks \& Spencer. \\
\hline Jailson Lira de Paiva (Copexvale) & Uva & Petrolina (PE) & GLOBALG.A.P \\
\hline Sun Group & Uva & Petrolina (PE) & GLOBALG.A.P, USAGAP, HACCP, Tesco. \\
\hline
\end{tabular}

Fonte: Trabalho de campo. Org. AUTOR

Da análise do quadro depreende-se que a certificação GLOBALG.A.P é de fato a mais adotada pelas empresas produtoras de frutas. Logo, a avaliação dessa certificação em específico gera impactos importantes no contexto da produção. A seguir relata-se brevemente como a certificação GLOBALG.A.P é aplicada e quais são as principais contradições e os impactos para a produção e comercialização.

Os auditores ao realizarem a inspeção para emitir a certificação GLOBALG.A.P devem seguir uma ampla lista de exigências contidas nos pontos de controle. Do total de 234 pontos de controle utilizados nas auditorias do GLOBALG.A.P, 117 são vinculados à segurança alimentar, 50 ao meio ambiente e biodiversidade, 46 ao controle da rastreabilidade e 21 relacionam-se diretamente ao bem estar dos trabalhadores.

Na prática, o cumprimento às regras do GLOBALG.A.P significa a necessidade de realizar investimentos vultosos nas fazendas para adequar toda a infraestrutura de packing house, o treinamento dos trabalhadores, o controle de pesticidas, entre outros. É justamente por esses critérios que começamos a identificar as primeiras contradições que envolvem a adoção de certificações privadas, pois os produtores, sobretudo os pequenos, não possuem as condições necessárias para se adequarem às normas da certificação. O exemplo mais eloquente foi colhido a partir de uma entrevista com um pequeno produtor do Perímetro Irrigado Nilo Coelho em Petrolina (PE). Na propriedade cultiva-se majoritariamente uva e manga para o mercado interno uma vez que as condições financeiras não permitirem a adoção da certificação GLOBALG.A.P. Para o produtor em questão, o custo da certificação é muito elevado. A depender do tamanho do estabelecimento o gasto total para a implementação de toda a infraestrutura condizente com as normas exigidas pelo GLOBALG.A.P pode chegar até R\$ 400 mil.

Outrossim, o entrevistado também destacou o fato de que a certificação não necessariamente agrega valor aos produtos, sendo mais uma questão de acesso ao mercado. Diante desse contexto, àqueles que optam por obter as certificações o fazem mais por obrigação do mercado externo do que por uma demanda efetiva.

A exigência de certificação de qualidade no Brasil é ainda pouco difundida em comparação com os mercados mais competitivos. Dessa forma, o que a pesquisa ajudou a revelar é que os produtores que adotam a certificação são somente aqueles que têm como foco a exportação. No contexto de crise econômica enfrentada na Europa, muitos produtores redirecionaram sua produção exclusivamente para o mercado interno, inclusive empresas multinacionais que atuam no setor da produção.

Por essa razão, as certificações internacionais tornam-se completamente desnecessárias, visto que os supermercados e demais pontos de varejo no Brasil não costumam exigir nenhuma certificação. $O$ que isso significa do ponto de vista da segurança dos alimentos? Enquanto os produtores certificados seguem determinadas normas quanto à presença de resíduos na produção e controle dos pesticidas, as frutas que seguem para o mercado interno 


\section{BEZERRA,J.E. \\ REDES DE SUPERMERCADOS E A GOVERNANÇA DO SETOR AGROALIMENTAR: A PRODUÇÃO DE FRUTAS NO NORDESTE BRASILEIRO}

devem atender critérios de "qualidade" que na sua ampla maioria não incorporam preceitos vinculados à segurança alimentar. Nesse caso, chama atenção que a fruta de qualidade é vista por muitos produtores como aquela que atende a requisitos, tais como: aparência, tamanho uniformidade, doçura etc.

Com relação à produção que segue para o mercado externo há uma maior fiscalização tanto por parte das certificações privadas como pelos agentes públicos. É comum o caso de produtores cuja produção é incinerada nos portos da Europa, após a fiscalização sobre a quantidade de resíduos ou mesmo alterações no grau brix das frutas.

A orientação principal pela qualidade desencadeou uma busca hercúlea por um ideal de qualidade que muitas vezes faz caminhar para uma artificialização do natural para responder à tara dos consumidores por uma fruta sem manchas, sem violações físicas, uvas sem sementes, abacaxis sem espinhos, melões em porções individuais, etc.

Os supermercados ao eleger a qualidade como um ideal a ser perseguido, transforma as certificações num verdadeiro instrumento de controle e "vigilância da produção" (AUTOR, 2012, p.195). Com isso, acabam por determinar novos parâmetros na organização dos processos de produção e de trabalho. Portanto, verifica-se uma espécie de regulação assistida por esquemas de certificação criados nos países compradores cuja influência na escala local entre pequenos, médios e grandes produtores é marcante. Tal prática condiciona os comportamentos, práticas e formas de trabalho ao cumprimento das normas presentes nos contratos entre importadores/supermercados e os produtores diretos. Do ponto de vista geográfico percebe-se claramente a existência do que Milton Santos (2002,p.80) chamava a atenção para a constituição de uma escala de realização das ações e a escala do comando.

\section{CONSIDERAÇÕES FINAIS}

As redes de supermercados configuramse como agentes chaves no controle da rede de produção de frutas tendo em vista seu poder como principal responsável pela compra das frutas, bem como por suprir o mercado europeu. Desse modo, observa-se a exclusão dos pequenos produtores dos canais de comercialização, a intensificação do trabalho com o intuito de garantir a sustentação da política de preços (guerra dos descontos) dos supermercados, passando pelas mudanças no processo produtivo a partir das exigências dos consumidores. Como corolário, o papel dos supermercados é fortalecido porquanto sua atuação no controle e "vigilância da produção" a partir da mercadificação dos sistemas de auditoria e certificação.

É necessário avançar na análise dos impactos das certificações e apontar os pontos positivos, bem como as limitações das certificações privadas no contexto da produção de frutas no Nordeste brasileiro. Alguns pontos positivos podem ser elencados ao tratar da difusão das certificações nas áreas de produção das frutas nos estabelecimentos certificados, a saber: melhor infraestrutura (alojamentos, refeitórios, etc.); maior controle para a segurança dos trabalhadores com a realização de treinamentos e a presença de profissionais voltados para a segurança no trabalho; maior regularidade no pagamento dos salários; entre outros.

Contudo, uma das grandes críticas relacionadas às certificações, sobretudo, à GLOBALG.A.P, é justamente a de não concentrar esforços mais precisos na proteção à saúde ambiental e a dos trabalhadores.

O que se verificou nas áreas de expansão da fruticultura no Nordeste é que a efetividade das certificações pode ser contestada no "lugar" da produção, justamente, a partir da persistência da precarização do trabalho. Afinal, os relatos de exploração excessiva dos trabalhadores por meio de longas jornadas, as experiências de contaminação com agrotóxicos, o assédio moral, as estratégias de impedimento da participação de sindicatos mais ativos e da organização dos trabalhadores são realizados por empresas que 


\section{BEZERRA,J.E. \\ REDES DE SUPERMERCADOS E A GOVERNANÇA DO SETOR AGROALIMENTAR: A PRODUÇÃO DE FRUTAS NO NORDESTE BRASILEIRO}

possuem certificações privadas e que fornecem frutas para as principais redes varejistas.

Para muitos, os supermercados não podem ser penalizados pelas irregularidades ambientais e trabalhistas encontradas em seus fornecedores, uma vez que, não são eles os responsáveis diretos pela produção. Porém, sabemos da sua posição de hierarquia na rede de produção das frutas e do seu poder em decidir quem está dentro ou fora do mercado; e de quais os critérios de produção devem ser seguidos. Daí a importância de aprofundar as pesquisas sobre o capital comercial, o crescimento do consumo e particularmente a ascensão dos supermercados.

\section{REFERÊNCIAS BIBLIOGRÁFICAS}

BEZERRA, Juscelino Eudâmidas. A fruticultura no Nordeste semiarido: internacionalização, conflitos territoriais e a precarização do trabalho. 2012. 376p. Tese (Doutorado em Geografia) Universidade Estadual Paulista, Presidente Prudente, 2012.

BEZERRA, Juscelino Eudâmidas; ELIAS, Denise de Souza. Difusão do trabalho agrícola formal no Brasil e sua dinâmica multiescalar. Investigaciones Geográficas - Instituto de Geografía. Universidad Nacional Autónoma de México, v. 76, p. 104-117, 2011.

BONANNO, A.; CAVALCANTI, J. S. B. . Globalization, Food Quality and Labor: The Case of Grape Production in North-Eastern Brazil. International Journal of Sociology of Agriculture and Food, v. 19, p. 37-55, 2012.

CAMPBELL, Hugh; LAWRENCE, Geoffrey; SMITH, Kiah. Audit Cultures and the Antipodes: The Implications of EurepGAP for New Zealand and Australian Agri-food Industries. In: MARSDEN, Terry, MURDOCH, Jonathan (Orgs.) Between the Local and the Global (Research in Rural Sociology and Development), v. 12, Emerald Group Publishing Limited, p.69-93, 2006.

CASTRO, Iná Elias de. Seca versus seca: novos interesses, novos territórios, novos discursos. In: CASTRO, Iná Elias de; GOMES, Paulo César da Costa; CORRÊA, Roberto Lobato (org.). Brasil: questões atuais da reorganização do território. Rio de Janeiro: Bertrand Brasil, 1996. p. 283-323.
COE, N.M.Global Production Networks. In: KITCHEN, Rob; THRIFT, Nigel (Orgs.). International Encyclopedia of Human Geography.London:Elsevier, Oxford, Vol.4, p. 556-562, 2009.

COE, N., Dicken, P. and Hess, M. Global Production Networks: Realizing the Potential. Journal of Economic Geography 8(3), p.271-295, 2008.

DORR, Andrea Cristina ; GROTE, U.The role of certification in the Brazilian fruit sector. Revista de Economia Contemporânea, v. 13, p. 539-571, 2010.

DIXON, Jane. Supermarkets as new food authorities In. LAWRENCE, Geoffrey; BURCH, David. (Orgs.). Supermarkets and Agri-food Suply Chains: transformations in the production and consumption of foods. London: Edward Elgar, 2007. p.29-50.

ELIAS, Denise. Regiões produtivas do agronegócio: notas teóricas e metodológicas. In: Julia Adão Bernardes; Catia Antonia da Silva; Roberta Carvalho Arruzzo. (Orgs.). Espaço e energia. Mudanças no paradigma sucroenergético. RJ: Lamparina, 2013. p.201-220. ELIAS, Denise. Les Territories de L'agrobusiness au Brésil. Confins (Paris), v. 15, p. 1-20, 2012.

ELIAS, Denise. Agricultura e produção de espaços urbanos não metropolitanos: notas teóricometodológicas. In: SPOSITO, Maria Encarnação B. (Org.). Cidades médias: espaços em transição. 1 ed. São Paulo: Expressão Popular (Coleção Geografia em Movimento), 2007.

FUCHS, D.; KALFAGIANNI, A. The Causes and Consequences of Private Food Governance. Business and Politics, 12 (3), p.1- 37, 2010.

FUCHS, D.; KALFAGIANNI, A.;ARENTSEN, M. Retail Power, Private Standards and Sustainability in the Global Food System, In: Jennifer Clapp and Doris Fuchs (eds.).Agro-Food Corporations, Global Governance and Sustainability. Boston: MIT Press,2009. p. 29-59.

HAVINGA, Tetty. Private regulation of food safety by Supermarkets. Law \& policy 28(4), p. 515-533, 2006.

HENSON, Spencer; HUMPHREY, John. Codex Alimentarius and private Standards. In: MEULEN, 


\section{BEZERRA,J.E. \\ REDES DE SUPERMERCADOS E A GOVERNANÇA DO SETOR AGROALIMENTAR: A PRODUÇÃO DE FRUTAS NO NORDESTE BRASILEIRO}

Bernd van der (Org.). Private food law: governing food chains through contract law, self-regulation, private standards, audits and certification schemes, Wageningen: Wageningen Academic Publishers,2011. p. 149-174.

HENSON, Spencer. The role of public and private Standards in regulating international food markets. Journal of International Agriculture Trade and Development. n.4,v.1, p.63-81,2008.

HUBBARD, P, KITCHIN, R, BARTLEY, B, FULLER, D. Thinking geographically: space, theory, and contemporary human geography. London: Continuum, 2002.

HUGHES, Alex. Geographies of exchange and circulation: alternative trading spaces. Progress in Human Geography, 29(4), p.496-504, 2005.

HUXLEY,Margo.Space and government: governmentality and geography.Geography Compass,n.5,v.2,p. 1635-1658, 2008.

IBGE, 2016. Produção Agrícola Municipal. Disponível em: https://sidra.ibge.gov.br/pesquisa/pam/tabelas . Acesso em Julho de 2016.

KALFAGIANNI, Agni, FUCHS,Doris..Global Gap. In: Business Regulation, Non-State Actors and Development, REED, Darryl; UTTING, Peter; MUKHERJEE-REED,Ananya. New York: Routledge, 2011.

LAWRENCE, Geoffrey; BURCH, David.Understanding supermarkets and agri-food supply chains. In. LAWRENCE, Geoffrey; BURCH, David. (Orgs.).Supermarkets and Agri-food Suply Chains: transformations in the production and consumption of foods. London: Edward Elgar,2007. p.1-28.
LESLIE, Deborah.Consumption. In: KITCHEN, Rob; THRIFT, Nigel (Orgs.). International Encyclopedia of Human Geography.London:Elsevier, Oxford, Vol.4, 2009. p.268-274.

PEGLER, L.J. Sustainable value chains and labour linking chain and "inner drivers" - from concepts to practice. ISS Working Papers Series. n.525, p.142, 2011.

Planet Retail Report. London: Planet Retail; 2012.

RAIS, 2016. Relação Anual de Informações Sociais. Disponível em: http://bi.mte.gov.br/bgcaged/login.php. Acesso em Março de 2016

RHODES,R.A.W. Understanding governance: ten years on. Organization Studies, v. 28, n. 8, p. 1243-1264, 2007.

RHODES, R.A.W. The new governance: governing without government. Political Studies, 44 (5),p.652-667,1996.

SANTOS, Milton. A Natureza do Espaço: técnica e tempo, razão e emoção. São Paulo: Edusp, 2002.

SELWYN, Ben. Globalized horticulture: the formation and global integration of export grape production in north east Brazil. Journal of Agrarian Change, Vol. 10, n. 4, p. 537-563, 2010

STOKER, Gerry. Governance as theory: five propositions. International Social Science Journal, 50(155), p.17-28, 1998.

VORLEY, Bill. Supermarkets and agri-food suply chains in Europe:partnership and protest In. LAWRENCE, Geoffrey; BURCH, David. (Orgs.). Supermarkets and Agri-food Suply Chains: transformations in the production and consumption of foods. London: Edward Elgar, 2007. p.243-267. 